\title{
Produções táticas de usuários e trabalhadoras de programa de saúde mental: estudo etnográfico num centro de saúde escola da zona oeste de São Paulo'
}

\section{Tactical productions of users and workers of mental health programs: an ethnographic study in a school health center in the west zone of São Paulo}

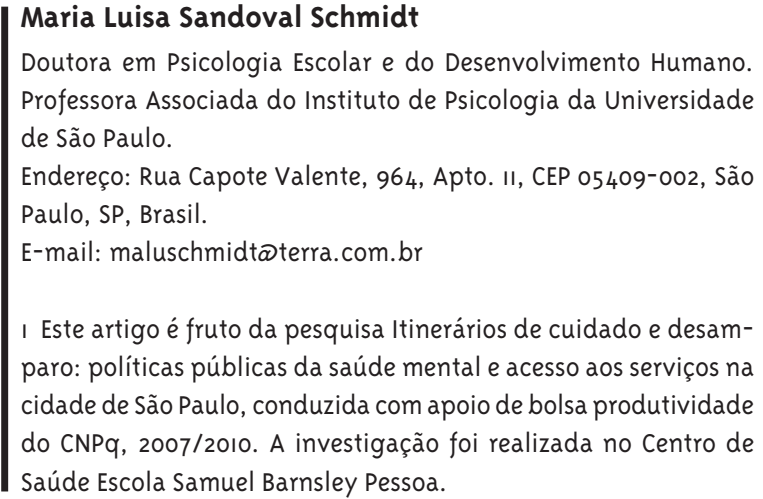

\section{Resumo}

Este artigo apresenta um recorte de pesquisa sobre o acesso aos serviços de saúde mental na cidade de São Paulo, focalizando as táticas de usuários e trabalhadoras do programa de saúde mental de um centro de saúde escola, constelando possibilidades e afrontando limites da política instituída. Tratou-se de estudo etnográfico realizado na recepção do referido programa, dando a conhecer dimensões das produções cotidianas que qualificam a participação de usuários e trabalhadoras na construção da política pública, na perspectiva posta em tema por Michel de Certeau. $\mathrm{O}$ artigo explicita, primeiramente, alguns nexos teórico-metodológicos que dão sustentação ao estudo, articulando a noção de tática, diferenças e tensões entre política instituída e formas de sua apropriação pela população e etnografia. Em seguida, apresenta o Programa de Saúde Mental no qual a pesquisa foi realizada, procurando mostrar seu caráter singular e "sobrevivente", tendo em vista as atuais orientações das políticas de saúde mental e de atenção básica. A interpretação do material observado teve como base as noções de indisciplina e de imaginário, examinando principalmente os vínculos, o mal-estar, a medicação, o acolhimento, o cuidado e o humor.

Palavras-chave: Políticas públicas de saúde; Saúde mental; Cotidiano; Michel de Certeau; Método etnográfico. 


\section{Abstract}

The article presents an outline of research on access to mental health services in São Paulo, focusing on the tactics of users and workers of a mental health program in a school healthcare center, constellating possibilities and confronting limits of the established policies. This was an ethnographic study conducted at the reception of the referred program, revealing the dimensions of everyday productions that qualify the participation of users and workers in the construction of public policy, on the perspective discussed Michel de Certeau. The article explains, first, some theoretical and methodological links that support the study, combining the concept of tactics, differences and tensions between instituted policy and its appropriation by the population and ethnography.

It then presents the Mental Health Program in which the survey was conducted, seeking to show its unique and "survivor" character, in view of the current policy guidelines on mental health and primary care. The interpretation of the observed material was based on the notions of discipline and imagination, examining primarily the bonds, the malaise, the medication, the reception, care and humor.

Keywords: Public Health Policies; Mental Health; Daily Life; Michel de Certeau; Ethnographic Method.

\section{Introdução}

Acompanhando as políticas públicas de saúde mental na cidade de São Paulo a partir do final da década de 1980, em que houve empenho na construção da rede alternativa de atenção no espírito da reforma psiquiátrica e da luta antimanicomial, é possível identificar uma crescente redução de sua presença na rede como porta de entrada do sistema. Trata-se, em outras palavras, de uma tendência de deslocamento da saúde mental da atenção primária para a esfera das especialidades ou como retaguarda no modelo de matriciamento das equipes de saúde da família.

O avanço do Programa de Saúde da Família (PSF) como primeiro acesso ao sistema de saúde foi seguido por duas tendências da reforma psiquiátrica: certo esgarçar da rede substitutiva, agravado pela dificuldade de organização e mobilização do movimento da luta antimanicomial, e o favorecimento do Centro de Atenção Psicossocial (CAPS) em detrimento da própria rede ${ }^{2}$.

Em São Paulo, a implantação do PSF, a partir de 2001, resultou na retirada progressiva das equipes de saúde mental das unidades básicas de saúde (UBS), limitando ou praticamente excluindo a saúde mental como atenção primária.

Assim, os serviços de saúde mental mantidos nas UBS foram desaparecendo, pois vinham sendo sustentados, em poucos lugares, por uma equipe mínima, às vezes desfalcada; em outros, por um profissional da área, psiquiatra ou psicólogo, atuando como especialista.

Ao mesmo tempo, observa-se a maior centralidade dos Centros de Atenção Psicossocial (CAPSs), contra a composição desses equipamentos com outros que fazem parte da tradição da área.

Essa situação, desenhada em traços largos, assinala a articulação entre o campo da saúde mental e a estratégia de saúde família (ESF) como fundamental para o atendimento das necessidades da

2 A rede substitutiva supõe uma composição não hierárquica e descentralizada de diferentes equipamentos e recursos institucionais e comunitários. Fazem parte de sua tradição equipes de saúde mental em unidades básicas, hospitais-dia, centros de atenção psicossocial, ambulatórios, enfermarias de psiquiatria em hospitais gerais, centros de convivência e residências terapêuticas, entre outros. A rede, no entanto, pode também ser concebida como arranjos pontuais de recursos que respondem à singularidade de uma situação. (Scarcelli, 1998; Freitas e Monteiro, 2006). 
população no contexto atual. No entanto, supõe-se que as ações dessa estratégia dependem da existência, justamente, da rede substitutiva que vem sendo desarticulada pelos sucessivos governos do município de São Paulo.

A cobertura da ESF é de 30\%, deixando de atender parte significativa da população paulistana. 0 enfraquecimento da rede substitutiva, por sua vez, com suas múltiplas possibilidades de cuidado pela escuta, grupalidade e convivência, representa também um empobrecimento das formas de responder às necessidades dos usuários do sistema de saúde ${ }^{3}$.

Nessa conjuntura os serviços capazes de oferecer atenção primária, em sistema de portas abertas, como programas ou equipes de saúde mental remanescentes em unidades básicas ou clínica escola de universidades públicas, enfrentam um assustador aumento de sua clientela. Ao mesmo tempo, sofrem com a dificuldade de constituir e contar com uma rede solidária de recursos complementares.

Os itinerários de procura por atendimento de parte da clientela que chega a esses serviços tornou-se tema da pesquisa da qual se apresenta, a seguir, um recorte focalizando as táticas de usuários e trabalhadoras do programa de saúde mental de um centro de saúde escola, constelando possibilidades e afrontando limites da política instituída.

0 artigo explicita, primeiramente, alguns nexos teórico-metodológicos que dão sustentação ao estudo, articulando a noção de tática, diferenças e tensões entre política instituída e formas de sua apropriação pela população e etnografia. Em seguida, apresenta o programa de saúde mental no qual a pesquisa foi realizada, procurando mostrar seu caráter singular e "sobrevivente" em vista das atuais orientações de políticas de saúde mental e de atenção básica.

Feitas essas exposições, dando um contorno à pesquisa de campo, passa-se à análise das produções de usuários e trabalhadoras do programa de saúde mental, incluindo o tema do humor.

\section{Tática, política instituída e etnografia}

A pesquisa teve como objetivo geral oferecer subsídios para avaliação das políticas públicas em saúde, particularmente em saúde mental, privilegiando as visões e as experiências de usuários dos serviços na cidade de São Paulo.

Como afirma Michel de Certeau (2008), existe uma disparidade entre "os espetáculos de estratégias globais e a opaca realidade de táticas locais" (p. 51). Em termos mais próximos do tema da pesquisa é possível entender que há distância e diferença entre os programas de saúde formulados nos gabinetes das Secretarias de Estado e sua efetivação no contato com os usuários. Há distância e diferença entre as estatísticas espetaculares e as vivências concretas de espera, desconforto, descaso e abandono por que passa a clientela. E existe ainda, graças à astúcia e à inventividade da população, transformações dos dispositivos de saúde tal como inscritos no papel pela ação dos heróis das pequenas apropriações que são seus usuários.

Buscou-se, pois, uma contribuição para a compreensão das políticas públicas que valorizasse e incorporasse as operações dos usuários que, ainda de acordo com Certeau (2008), marcam de maneira singular a prática social. Nesse caso, aquela do cuidado em saúde.

Partiu-se, então, da convicção de que os usuários não são passivos diante da organização dos serviços que lhes são oferecidos na saúde pública.

A noção de tática foi trazida como modo de ter acesso àquela produção dos usuários que, normalmente, permanece invisível e silenciosa. Algumas ações - que podem resultar em fracasso ou sucesso na obtenção do cuidado que se requer - são antidisciplina ou uma espécie de desobediência às normas e exigências das instituições de saúde em favor de interesses e regras próprias, bricolagem de elementos oriundos de diferentes esferas (saber especializado,

3 Pereira e colaboradores (2008) entendem, a partir da análise sócio-histórica das políticas públicas de saúde mental no Brasil, que a atual proposta de rede substitutiva "centrada" no CAPS e a transferência da atenção primária em saúde mental para a estratégia de saúde da família atende melhor, mas não totalmente, aos "pacientes com transtornos graves", deixando aqueles com "transtornos moderados e leves” sem alternativas de atendimento adequado às suas demandas. 
práticas de cura populares e religião, por exemplo) para responder a uma necessidade pontual ou ideações imaginárias confrontando a racionalidade do sistema de saúde. As táticas permitem focalizar as apropriações que os usuários fazem dos serviços de saúde em um circuito mais amplo de recursos pessoais, sociais e culturais, dos quais laçam mão para obter alguma resposta para o sofrimento.

Recorrendo à distinção que Certeau (2008) faz entre estratégias e táticas, foi possível delimitar os objetivos específicos da investigação.

Para o autor, as estratégias são próprias daqueles que têm poder na ordem institucional e visam, sobretudo, garantir o lugar desse poder. As táticas, por sua vez, são ações dos que não têm lugar e "aproveitam" as ocasiões. A lógica da estratégia é formada em torno do lugar que alguns ocupam, enquanto a lógica da tática é articulada sobre uma conjuntura e sobre a vontade do outro, agindo no território ou no lugar estruturado e controlado por esse outro. Por isso é possível fazer uma leitura das táticas como modos de habitar o lugar do outro. Nas palavras de Certeau:

Em nossas sociedades, elas (as táticas) se multiplicam com o esfacelamento das estabilidades locais como se, não estando mais fixadas por uma comunidade circunscrita, saíssem de órbita, se tornassem errantes, e assimilassem os consumidores a imigrantes em um sistema demasiadamente vasto para ser o deles e com as malhas demasiadamente apertadas para que pudessem escapar-lhe (Certeau, 2008, p. 47).

O enfrentamento da doença e do sofrimento por parte da população que depende do sistema público pode ser compreendido por este viés das ações táticas, que abrem os modos de habitar o sistema institucionalizado de serviços e equipamentos de saúde. 0 acesso ao atendimento, por seu turno, pode ser visto como resultado, então, da dinâmica e das negociações cotidianas entre os lugares organizados pelas políticas públicas e as táticas de apropriação dos usuários.

A metodologia para aproximar-se desse cotidiano foi uma etnografia realizada junto ao programa de saúde mental de um centro de saúde escola da zona Oeste da cidade de São Paulo. Esse método supõe o deslocamento do pesquisador e sua permanência, por um tempo relativamente prolongado, no espaço de vida de um outro social e culturalmente próximo ou distante, cuja existência ele deseja compreender. Essa permanência no campo, a que se pode chamar de observação participante, nasce do legítimo interesse pela alteridade e da abertura para a autorreflexão em que o pesquisador busca, a um só tempo, situar-se quanto aos significados e sentidos das ações do outro e compreender criticamente os efeitos de sua presença estrangeira (Clifford, 2002; Geertz, 1989; Oliveira, 200o; Schmidt, 2006).

A escrita etnográfica - ocasião para recolher, interpretar e transmitir a experiência do campo - apresenta-se como anotação de modos de viver, sentir e pensar, mergulhados nas interrogações sobre seus significados (Geertz, 1989). A inscrição em texto das produções de usuários e trabalhadoras faz-se, portanto, procurando mostrar falas e gestos cotidianos que constituem e questionam a política instituída.

Condutas táticas são formas de tomar posse, temporariamente, de lugares instituídos sem, contudo, jamais se estabelecerem ou fixarem legitimamente como partes da instituição: invasões instáveis e precárias da ordem institucional. Como elas, o texto em que se abrigam aspira atrair para si a vocação para exibir as franjas do instituído, na esperança de oferecer instáveis e precárias pistas de sua existência.

A observação participante foi realizada na recepção do programa, de agosto a dezembro de 2009, em períodos semanais de quatro horas. Nessa observação, o contato mais frequente foi com cinco auxiliares de enfermagem encarregadas da recepção, duas psiquiatras que já tinham sido entrevistadas em outra etapa da pesquisa e uma terapeuta ocupacional. 0 número de usuários variava a cada período e o convívio com eles ocorria tanto na sala de entrada do programa, de modo mais informal, quanto na assistência às entrevistas conduzidas pelas auxiliares de enfermagem.

A recepção de saúde mental escuta as pessoas que buscam pela primeira vez atendimento, mas também conversa com todos que, já sendo usuários do programa, chegam com questões e demandas emergentes, fora do horário de suas consultas ou terapias.

As entrevistas são conduzidas pelas auxiliares de enfermagem e podem ou não derivar em consulta 
com psiquiatras. Além do acompanhamento dessas entrevistas, o trabalho de campo incluiu a presença em interconsultas com psiquiatras e outros setores do centro de saúde, leitura de prontuários, conversas com auxiliares de enfermagem, estagiários, aprimorandas, equipe de especialistas, parentes de usuários e usuários.

O cotidiano visto e vivido desde a porta de entrada do programa de saúde mental permitiu alcançar regiões interessantes de ação e produção dos usuários, abarcando, ainda, aquelas dos profissionais e outros indivíduos que gravitaram em torno da sala de acolhimento.

As táticas das trabalhadoras da "linha de frente" - as auxiliares de enfermagem - foram recolhidas no texto, pois suas atividades são direta e constantemente marcadas por tensões, oposições e identificações próprias do lugar que ocupam como mediadoras e tradutoras das necessidades da população junto aos especialistas.

\section{O programa de saúde mental}

Atualmente, o programa de saúde mental no centro de saúde é uma exceção, tendo em vista a hegemonia da estratégia de saúde da família na atenção primária e a "superação" conceitual da organização dos serviços por programas. A saúde mental na atenção primária assinala um modo singular de relação do centro de saúde escola com as políticas públicas em que se combina a acolhida do novo no tradicional.

A estrutura administrativa da unidade estudada contemplava, até a passagem de sua gestão a uma organização social (OS), em 2010, a influência de quatro departamentos da faculdade de medicina à qual está ligado, e que, historicamente, vinham dialogando em torno de concepções e modos de fazer. Olhando a história da implantação nesse centro da saúde da família, bem como aquela, mais antiga, da saúde mental, nota-se uma prática constante de negociação e debate em torno de mudanças e introdução de novidades envolvendo setores dos departamentos e os trabalhadores. 0 experimento de manutenção da saúde mental como porta de entrada do sistema ou como atenção primária pode ser visto, nesse contexto, como uma espécie de resistência, não à inovação ou renovação das propostas, mas à “política de terras arrasadas" que tem o hábito de jogar fora tradições e experiências valiosas em nome da "modernização".

Seguindo a tendência do centro de saúde escola, a área de saúde mental tem formas de transmissão de sua história, dos conhecimentos e das práticas que, como memória viva, tecem o antigo e o novo, permitindo inserir com consistência gerações mais recentes de profissionais. Conservando a memória de práticas de atenção primária no atendimento direto à população, procura, de maneira concomitante, responder às especificidades do momento atual, criando espaços de trabalho e formação junto aos agentes comunitários de saúde, na acepção do matriciamento.

Contudo, o serviço sofre com a alta demanda e o risco da intensa psiquiatrização. A alta demanda, questão compartilhada com outros serviços que acolhem ou procuram acolher quem chega, é composta, sobretudo de indivíduos cujo sofrimento é grave, mas não exclusivamente. Há quem queira ou precise, basicamente, conversar sobre suas dificuldades de viver.

Apontada como um problema pela coordenadora do programa, a preponderância do atendimento psiquiátrico aparece no número maior de profissionais com essa formação. Tal configuração, por sua vez, denuncia o enfraquecimento do ideário multiprofissional e interdisciplinar da reforma psiquiátrica e o perigo de tratar com medicamentos padecimentos de ordem social e existencial.

No entanto, é preciso acenar com alguma perspectiva de abrandar o sofrimento dos usuários, diante das poucas alternativas de atendimento individual ou em grupo, com a colaboração da psicologia, terapia ocupacional e assistência social, entre outras disciplinas que historicamente participaram de experiências fecundas de atenção e cuidado no campo da saúde mental.

A medicação acaba por ocupar lugar central porque traz promessas de alívio; e as consultas psiquiátricas são frequentes, consistindo, junto com as entrevistas de recepção, em grande parte da atividade do setor.

A necessidade de cobertura pressiona as condutas de acolhimento. Mesmo assim, na visão das trabalhadoras é notável como a população procura 
caminhos: o programa de saúde mental parece ser um lugar em que as astúcias para conseguir o que se quer aparecem com menor censura.

Em contrapartida, a recepção, constrangida pela grande e complexa procura por atendimento, é pulsante, forte e viva principalmente pela sustentação da enfermagem, como disse uma médica. Em meio aos efeitos danosos provocados pelo aumento da demanda e pela diminuição das equipes, a recepção potencializa continência e acolhida, pela negociação habilidosa das relações entre enfermagem e população usuária.

\section{Produção dos usuários: mal-estar, remédio e vínculo}

Nas entrevistas de recepção um tema que aparece frequentemente como fonte de sofrimento, motivando a procura de auxílio na saúde mental, é a falta de diagnóstico. A ausência de explicação e de caracterização de uma doença precisa é aflitiva e está associada à dificuldade de encontrar abrandamento de um mal-estar cujo sentido, muitas vezes, escapa àquele que o vive.

Alguns usuários descrevem verdadeiros périplos por hospitais, especialistas e exames que, longe de esclarecer e aliviar a dor, confundem e desorientam. Uma senhora sente-se agoniada pelo fato de ter sido enviada de um hospital a outro sem entender a razão: desconfiava que os médicos escondiam a gravidade de sua doença e sofria com as contradições nas recomendações de diferentes médicos dos quais dependia para obter licenças e direitos trabalhistas.

Assim, ter de contornar a discrepância entre as orientações de dois médicos que a acompanham quanto à conveniência ou não dela retomar o trabalho e a necessidade de laudos e exames para obter licença médica, benefícios do INSS e carteirinha para ônibus colocam-na em um impasse: se não voltar a trabalhar não tem o dinheiro para fazer os exames; se não tem os exames não consegue os benefícios sociais a que tem direito. A demora no agendamento de consultas retarda a obtenção desses benefícios. $\mathrm{Na}$ entrevista, fica exposta uma dupla demanda: conseguir os laudos e exames; e "reclamar" dos problemas do sistema de saúde, delineando, se possível, uma solução para si.
A saúde mental, para muitos usuários, se apresenta como mais uma especialidade médica. No entanto, trata-se de uma especialidade percebida ou intuída como propícia ao esclarecimento daquilo que nos roteiros de suas buscas por atendimento vai se tornando obscuro e confuso: consultas psiquiátricas escutam e ajudam a clarificar histórias de adoecimento e tratamento, facilitando a ordenação de condutas e orientação de usuários e seus parentes no encaminhamento de um cuidado mais adequado.

Tem-se um exemplo interessante da apropriação das entrevistas de recepção e das consultas psiquiátricas pelos usuários, que aproveitam a oportunidade de uma escuta mais ampla e plástica para falar e tratar de assuntos e questões silenciados em outros espaços do sistema de saúde ou, mesmo, neles originados.

As experiências de sofrimento comportam uma exuberância de sensações no corpo, descritas singularmente: queimação nos olhos, tontura, sufocamento, sensação de choque no corpo, falta de ar, insônia, aflição que começa na frente e vai para o pescoço e impede de ouvir os outros, dores nos braços e nas pernas, palpitações, lerdeza, visão atrapalhada. A prevalência, nas entrevistas acompanhadas, do mal-estar localizado no corpo chamou a atenção e levou a pensar nos modos de sofrer associados à imaginação em torno das formas de se cuidar.

A expectativa de melhora não está, essencialmente, ligada a uma ideia clara e unívoca sobre a natureza de uma terapêutica psicológica, "da alma ou da cabeça”. A conversa nas entrevistas, quase sempre, privilegia a descrição dos males e não motivos, razões ou teorias que possam explicá-los: a fala projeta-se como lance ou jogada decisiva para obter o tratamento e sua capacidade de impactar ou impressionar o ouvinte; como testemunham as auxiliares de enfermagem, é relevante na avaliação da gravidade ou da urgência de cada "caso". Insistir e exigir também são, certamente, modos de conseguir atendimento.

Solicitados a falarem sobre alguns itens de um roteiro da entrevista de recepção - motivo da ida ao programa; concepções, causas e consequências do problema vivido; formas de encarar, aguentar ou melhorar a situação e expectativas quanto à ajuda -, alguns usuários ocupam o tempo narrando mais 
detidamente a vida que vêm levando; outros, no entanto, mostram não ver sentido nas tentativas de estabelecer conexões entre a vida que levam e os males que vivem no corpo. Nessas posições, que assinalam os polos de um diversificado espectro de pontos intermediários, há, talvez, um denominador comum representado pelo desejo de conseguir a consulta médica.

É pela consulta psiquiátrica que a grande maioria das pessoas se torna usuária do programa, ingressando em uma rotina ditada, principalmente, pela administração de medicamentos e seu acompanhamento. Há uma infinidade de coisas acontecendo em torno do remédio, na recepção: buscar ou trocar receita, solicitar medicação fora do prazo de retorno ou extra, tentar atendimento no centro de saúde escola para obtê-lo gratuitamente, pegar remédio para algum parente, tomá-lo na forma injetável.

Os usuários não são passivos na relação com o remédio: administrá-lo em maior ou menor dose dependendo da intensidade do desconforto é uma ação comum que, algumas vezes, gera a necessidade de solicitar uma dose extra ou permite adiar a ida ao serviço. Para muitos, a dependência ao medicamento implica avaliação do dispêndio de tempo e trabalho para sua obtenção, sendo vantajoso encontrar um serviço de saúde que, como o centro de saúde escola, não é burocrático em sua liberação. Assim, o remédio aparece nas relações entre usuários e profissionais de saúde, especialmente médicos e auxiliares de enfermagem, como mediador potente.

Para a prática psiquiátrica, trata-se de um enfrentamento dos sintomas ou de um suporte necessário à condução de vidas, sem os quais os pacientes submergem na desorganização mental e no delírio. Mas, ao mesmo tempo, é sensível a preocupação com a intensa medicalização a que a prática é empurrada, por causa da impossibilidade de atender à alta demanda por psicoterapia.

Nesse sentido, o remédio está incorporado à vida e ao modo de sentir de muitos usuários. Na sala da recepção, uma usuária faz um comentário interessante e revelador da identificação do remédio com um modo de cuidar naturalizado: Estou com a boca seca, não sei se pelo remédio ou se pelos nervos. Para essa mulher, em certas circunstâncias, o remédio não se distingue do mal que pretende curar.
Outro usuário de muito tempo do programa expõe, talvez, a contrapartida da naturalização do remédio. Ele teve alta da psiquiatra e passou para saber sobre psicoterapia, pois, depois de pensar bem, achou que deveria fazê-la. Diz que é difícil traduzir em palavras o que sente: mistura o real e o não real e, às vezes, pode ficar agressivo. Por fim, arremata: o remédio parece que arrumou por fora, mas não por dentro. Em sua conclusão recorta a existência de um dentro, resguardado da influência do remédio. Esses episódios indicam uma fecunda atividade imaginária afrontando a lógica médica e científica, ancorada na singularidade das experiências de uso de medicações. A recepção dá a medida dos vínculos que se estabelecem e se perpetuam pela frequência dos usuários ao serviço. Há, para além da rotina em torno dos remédios, a regularidade de consultas com psiquiatras, psicóloga e terapeuta ocupacional. Algumas oficinas, talvez menos regulares, porque dependem de materiais nem sempre disponíveis, também são referências no cotidiano da clientela.

É perceptível a apropriação que usuários mais antigos fazem do serviço, bem como a natureza expandida de seus vínculos que transcendem o tratamento em si. Duas irmãs, com dificuldades grandes de lidar com a vida prática, ligam para a recepção e pedem orientação para as auxiliares de enfermagem quando se deparam com um problema intransponível para seus recursos. Por exemplo, certa vez perderam a chave da casa e, sem saber o que fazer, recorreram às auxiliares de enfermagem.

Quem chega mostra-se, em geral, à vontade no serviço. E os usuários de longo tempo o têm como lugar familiar. Apesar das dependências físicas acanhadas, a recepção e sua extensão numa sala de repouso, que contém uma maca e cobertores, são também usadas como lugar de permanência ou de passagem, para um momento de urgência ou de sofrimento mais intenso.

O vínculo de confiança tecido nas relações concretas entre usuários e equipe de saúde mental constitui o espaço do setor como lugar habitado, no qual os usuários têm relativa mobilidade.

As tensões, por outro lado, aparecem mais claramente na linha de frente, nas relações entre auxiliares de enfermagem e usuários, que, algumas vezes, manifestam descontentamento em serem atendidos 
por elas e não pelos médicos ou médicas.

Ações que poderiam ser entendidas como indisciplina, no sentido das táticas usadas pela população para adequar o sistema de saúde às suas necessidades, são percebidas pelas auxiliares no dia a dia. Gestos como falsificar ou rasurar uma receita, telefonar várias vezes para tentar obter o que se quer apostando na variação de posições entre diferentes profissionais, omitir a mudança de endereço para permanecer no serviço ou não mostrar o cartão para não ver denunciada a falta a uma consulta agendada foram relatados pelas auxiliares que costumam encará-los com um misto de ironia e tolerância. Não comparecer a uma consulta marcada e aparecer "fora de hora" é uma prática comum entre a clientela, numa tentativa, talvez, de subverter o regime de agendamento prévio, procurando atendimento seguindo premências subjetivas. Gestos como esses causam indisposição nas auxiliares de enfermagem, mas a vontade de cuidar introduz um diferencial importante que se sobrepõe a uma eventual necessidade ou intenção de controlar.

A "descoberta" de "indisciplinas" como resultado de pesquisa remete à reflexão sobre o elo de confiança construído entre usuários e trabalhadores da saúde mental. Isso, de certa maneira, enlaça também a pesquisadora, em quem se confiou como parceira na tarefa do cuidado.

Interpretar as táticas de indisciplina como ações criativas da população diante das limitações do sistema de saúde e como pistas para o esclarecimento de suas necessidades pode ser um modo de responder àquela confiança acima referida. Tomá-las como mero problema administrativo teria, provavelmente, um significado diverso: servindo ao controle, depreciaria o cuidado.

\section{Produção da equipe de saúde mental: acolhimento, cuidado e vínculo}

As táticas de apropriação do serviço de saúde mental por parte dos usuários correspondem ações das auxiliares de enfermagem na recepção, e de outros profissionais no atendimento.

A flexibilidade das auxiliares para responder às situações que se apresentam pode ser lida como uma autonomia para a invenção de formas de cuidar contra a rigidez burocrática de regras que, em geral, excluem usuários que nelas não se encaixam. Essa flexibilidade pode ser interpretada, também, como indisciplina: uma indisciplina institucional decisiva para o acolhimento que a singularidade e a pluralidade dos usuários requerem.

A coordenadora do programa explicita uma questão crucial, quando perguntada sobre a prática de encaminhamento de usuários: aqui o céu é o limite!. Ela o diz reconhecendo a dificuldade de encaminhar e de estabelecer limites para o número de pessoas atendidas.

As auxiliares atendem pessoas no momento da procura, mesmo sem agenda, sempre que entendem que elas não vão aguentar esperar ou, pior, serão dispensadas ou encaminhadas. Uma médica do programa assinalou que a enfermagem, no e para o programa de saúde mental, constitui-se em especialização, construída em longos anos de serviço.

A confiança na experiência evidencia-se na condução das entrevistas em que as auxiliares de enfermagem são capazes de ouvir histórias, sustentar silêncios e compreender demandas, amalgamando conhecimento e intuição. A percepção dos impactos e das ressonâncias da situação do usuário em seus modos de escutar e acolher, as tentativas de imaginar-se no lugar do outro e a proximidade da posição social em que se encontram na relação com a população são elementos, entre outros, que sedimentam o valor da experiência na formação das auxiliares de enfermagem.

O cuidado, por sua vez, é pensado como algo a ser oferecido mesmo quando não há esperança de mudança ou superação do sofrimento. Ele se manifesta, para além da escuta, no uso intenso e interessante dos prontuários que abrigam relatos dos usuários em seu trânsito pelo centro de saúde; na preferência pela escritura de relatos de entrevistas e outros episódios ligados ao atendimento, ao invés do recurso ao preenchimento de formulários que raramente conseguem transmitir uma imagem da pessoa, pálida que seja; na movimentação pelo centro de saúde, acompanhando usuários ou em busca de seus prontuários; na ajuda àqueles com maiores dificuldades na marcação de exames e outras providências em outros setores; na negociação com outros programas 
para facilitar a vida dos pacientes; na chamada de usuários que tiveram alguma alteração significativa em exames que não vieram buscar; na tolerância com atrasos e confusões de agenda quando sabem que os usuários se atrapalham por conta de suas dificuldades.

Particularmente a escrita e a leitura dos prontuários chama a atenção, pois se trata de um recurso de comunicação e de ligação entre a saúde mental e outros setores e no interior do próprio programa. É frequente o aproveitamento de "janelas" nos horários de entrevista para colocar a escrita dos relatos nos prontuários em dia. Consultados com frequência, trazem anotações sobre a vida dos usuários e de seus itinerários de tratamento, servindo como importantes referências para o esclarecimento da situação de cada um.

$\mathrm{O}$ vínculo com a população, fundamento da atenção e do cuidado oferecidos pelas auxiliares de enfermagem, é ao mesmo tempo fonte de angústia, uma vez que, para essas profissionais, é difícil ou mesmo impossível ficar indiferente ao sofrimento e às demandas dos usuários.

No enfrentamento das adversidades e vicissitudes do cotidiano da recepção, o humor apresentou-se, na pesquisa, como uma dimensão a ser considerada: arte de fazer astuta e criadora nas relações com a clientela.

\section{Humor}

O humor revelou-se substância preciosa e constante no cotidiano da recepção do programa de saúde mental. Se, como acredita Certeau (2008), as táticas são "achados alegres, poéticos e bélicos" (p. 104) o humor tem com elas grande afinidade.

As auxiliares de enfermagem, mas não exclusivamente, têm um modo peculiar de introduzir uma observação ou história engraçada, distendendo, por um instante, a atmosfera tensa e pesada que algumas vezes se instala na recepção de usuários em situação de muito mal-estar. É quase como um respiro, uma tomada de fôlego, uma distração.

A qualidade quase sempre respeitosa e raramente ofensiva da graça é notável. Soma-se a isso a capacidade e a espontaneidade de rir de si mesmas e de rir com os outros, da graça que algumas vezes os usuários fazem em torno de algum tema em pauta.

Numa conversa na sala de recepção uma moça fala do irmão dependente de álcool, descreve a situação difícil do rapaz e da família em função dos delírios e alucinações que ele encena. A auxiliar pergunta se o rapaz vê bichos e a moça responde, risonha: Vê! Outro dia ele viu um rato de bermuda! 0 riso instala-se diante da imagem e a cena lança a todos para fora do ambiente opressivo e assustador das quatro paredes do cômodo onde o rapaz delira, atrás da corrida louca de um rato de bermuda.

Estagiárias do curso de psicologia associaram o riso, o dito jocoso, a piada à criação de uma atmosfera mais leve, algo que faz levitar, por instantes, assuntos e histórias pesadas. Nesses casos, parece que imagens absurdas e engraçadas funcionam como saídas da situação difícil: são como que pequenas fugas para outra realidade na qual o impossível acontece, apostas num encontro de delírio e humor.

O humor é algumas vezes ácido, como se rebatesse a dureza da vida com uma radicalização ainda maior dessa dureza. Não se trata de tornar algo leve, mas apenas risível. 0 dispositivo parece ser, nesse caso, exagerar aquilo que por si já é excessivo.

Um rapaz conta uma longa história sobre as dificuldades para agendar e realizar uma cirurgia em sua mãe e termina com a frase: Por isso o desarmamento. Diante dos olhares de interrogação, explica: Porque, se a pessoa tem uma arma, ela mata um. A ironia dispensa outras explicações e funciona como uma crítica que toma o próprio sistema de saúde como alvo e motivo do riso: trata-se de um sistema de saúde que "é de matar".

Bergson (2007), em livro que se tornou um clássico sobre a comicidade, defende a tese de que o riso, aparentemente uma prerrogativa exclusivamente humana, representa uma espécie de punição social a atitudes e comportamentos automatizados de homens e mulheres. 0 riso é expressão de desaprovação social diante de humanos que se conduzem como máquinas.

Essa visão é interessante para compreender alguns episódios em que uma função crítica se apresenta. Uma auxiliar de enfermagem entra rindo na sala da recepção, vinda do corredor e comenta: Acontece cada uma com a gente, mas eu precisava do prontuário... Conta, então, que quase levou a porta 
na cara, pois foi correndo atrás da psiquiatra sem que ela a visse. Segue-se uma série de comentários bem-humorados sobre a disputa pelos prontuários: empresta-se até o paciente; o prontuário não. A auxiliar ri de seu desajeitamento, numa espécie de autocrítica cujo objeto é o agir sem pensar.

Em outra ocasião, um homem chega querendo marcar uma consulta psiquiátrica. Uma auxiliar explica que o serviço está sem agenda para novos pacientes até o ano seguinte. E acrescenta que a situação vai piorar, pois a prefeitura está retirando médicos do centro de saúde. O homem pergunta: O que posso fazer? Vou procurar outro lugar? A auxiliar responde: Você pode lutar com a gente. $\mathrm{Na}$ continuidade da conversa, o homem esclarece que se trata com um psiquiatra particular que lhe prescreveu uma lista enorme de exames que ele não pode pagar. Por isso veio ao centro de saúde, imaginando que pudesse fazer os exames sem pagar. As auxiliares entendem que ele poderia fazer os exames no centro de saúde, só não compreendem porque ele foi enviado para a saúde mental e não para a saúde do adulto, na qual teria facilidade para solicitar os exames. Uma delas pega a lista assinalada pelo médico particular e exclama: Aqui está marcado até teste de gravidez! Todos riem, inclusive o homem, que, não sendo jovem, fala que já passou da idade de ficar grávido.

$\mathrm{O}$ assinalamento incorreto do teste de gravidez condensa ou metaforiza o automatismo do trabalho, e o riso parece responder de modo crítico e amplo aos efeitos desse automatismo em vários contextos: da política de governo que age segundo uma norma administrativa incapaz de discriminar singularidades; da ação mecânica de um médico marcando exames numa lista pré-formulada; dos setores do centro de saúde que não olham com atenção para o pedido e fazem um encaminhamento estapafúrdio.

Esses breves apontamentos sobre o humor, fechando o percurso até aqui empreendido em torno de táticas de usuários e trabalhadoras de um programa de saúde mental, vêm reforçar, espera-se, o interesse e a pertinência do estudo e da compreensão das ações cotidianas na construção das políticas públicas de saúde.

\section{Agradecimentos}

Agradeço às equipes do Programa de Saúde Mental e do Projeto São Remo a acolhida e a preciosa colaboração em todas as etapas da pesquisa. Esclareço, ainda, que a identificação do centro de saúde foi acordada com as profissionais e suas chefias, seguindo uma prática comum naquela instituição.

\section{Referências}

BERGSON, H. O riso: ensaio sobre a significação da comicidade. São Paulo: Martins Fontes, 2007.

CERTEAU, M. A invenção do cotidiano: artes de fazer. Petrópolis: Vozes, 2008.

CLIFFORD, J. A experiência etnográfica: antropologia e literatura no século XX. Rio de Janeiro: UFRJ, 2002.

FREITAS, M. G.; MONTEIRO, M. Las redes comunitárias. In: MONTEIRO, M. G. (Org.). Teoria y practica de la psicologia comunitária: la tensión entre comunidad y sociedad. Buenos Aires: Paidós, 2006. p. 1-13.

GEERTZ, C. A interpretação das culturas. Rio de Janeiro: Livros Técnicos e Científicos, 1989.

OLIVEIRA, R. C. O trabalho do antropólogo. Brasília, DF: Paralelo 15; São Paulo: Unifesp, 2000. PEREIRA, L. M. F.; RIZZI, H. J.; COSTA, A. C. F. Análise sócio-histórica das políticas públicas em saúde mental no Brasil. In: LANCMAN, S. (Org.). Políticas públicas e processos de trabalho em saúde mental. Brasília, DF: Paralelo 15, 2008. p. 29-86.

SCARCELLI, I. R. O movimento antimanicomial e a rede substitutiva em saúde mental: a experiência do município de São Paulo: 1989-1992. 1998. Dissertação (Mestrado em Psicologia Social) Instituto de Psicologia da Universidade de São Paulo, São Paulo, 1998.

SCHMIDT, M. L. S. Pesquisa participante: alteridade e comunidades interpretativas. Psicologia USP, São Paulo, v. 17, n. 2, p. 11- 41, 2006.

Recebido em: 03/09/2012

Aprovado em: $01 / 04 / 2013$ 